\title{
O MEIO AMBIENTE NO SISTEMA CONSTITUCIONAL BRASILEIRO
}

\author{
Eunice Aparecida de Jesus Prudente \\ Professora Assistente do Departamento de Direito do Estado da Faculdade de \\ Direito da Universidade de São Paulo \\ Analista Técnico Senior I da Empresa Metropolitana de Planejamento da Grande \\ São Paulo, EMPLASA
}

\begin{abstract}
Resumo: O Meio Ambiente equilibrado e sadio constitui direito fundamental do povo. Bem de uso comum do povo nos termos da Constituição Federal em vigor. A poluição ambiental é um dos mais graves problemas brasileiros. Existe legislação específica, mas esta tem sido ineficaz, sobretudo quando a fonte poluidora é o exercício de atividades econômicas. Urge a revogação da atual por legislação nova, com base nos ditames da Constituição Federal de 1988. Impõe-se também a acolhida, pela futura legislação das comprovações tecnocientíficas que já dispomos sobre ecologia e aquiescência das recomendações dos movimentos populares ambientalistas.
\end{abstract}

Résumé: L'environnement sain et equilibré est un droit fondamental du peuple. Bien d'usage commun, selon les dispositions de la Constitution Fédéral en vigueur. La pollution de l'environnement est parmi les plus sérieux problemes brésiliens. Il existe une législation spécifique, mais celle-ci n'a pas été éficace, surtour quand la source de pollution découle de l'éxercice d'activités économiques. C' est urgent la révogation de la législation actuelle por une nouvelle, élaborée selon les règles de la Constitution Fédérale de 1988. Il s'impose aussi l'anéxation, à la future législation, des comprobations tecno-cientifiques desquelles on a déja pris conaissance sur l'écologie et l'accueil des recommandations des mouvements populaires pour l'environnement.

Unitermos: Constituiçāo; Direitos Humanos Fundamentais; Meio Ambiente; Poluição; Competência Concorrente entre União e Estados Membros da Federação.

\section{INTRODUÇÃO}

\section{Importância do Tema}

A dignidade da pessoa humana encontra-se entre os fundamentos do Estado Democrático de Direito, estabelecido entre nós, com o advento da Constituição Federal de 1988. Não há que se falar em respeito ao brasileiro sem lhe garantir o direito à vida, a partir de certas previsões necessárias à subsistência, onde o ar, a água, entre outros, são imprescindíveis e dependerão de um meio ambiente sadio. 
Nota-se verdadeira coincidência entre os objetivos fundamentais da República Federativa do Brasil e os princípios impostos à ordem econômica, respectivamente:

Art. $3^{9}$

"I construir uma sociedade liṿre, justa e solidária;

II garantir o desenvolvimento nacional;

III erradicar a pobreza e a marginalização e reduzir as desigualdades sociais e regionais;

IV - promover o bem de todos, sem preconceitos de origem, raça, sexo, cor, idade, e quaisquer outras formas de discriminação;"

Art. 170

"I - soberania nacional;

II propriedade privada;

III função social da propriedade;

IV - livre consciência;

$\mathrm{V}$ - defesa do consumidor;

VI - defesa do meio ambiente;

VII - redução das desigualdades regionais e sociais;

VIII - busca do pleno emprego;

IX - tratamento favorecido para as empresas brasileiras de capital nacional de pequeno porte".

E, é bom que assim seja, significa que providências com vistas à distribuição de rendas e terras já forem iniciadas, possuem amparo legal e consenso dos cidadãos, legitimamente representados no Congresso Constituinte de 88.

Cumpre salientar que a "defesa do meio ambiente" $\varepsilon$ agora listada entre ditames a serem observados pela atividade econômica, e apontada em suas diversificadas formas com razāo, como "vilä" na luta pela preservação ambiental. As exceções existem, preciosas, porém confirmam a regra.

Há muitos cientistas ambientalistas renomados, bem como entidades civis vêm denunciando a ausência de controles, pelo Estado, sobre a poluição ambiental, sobretudo a provocada por atividades industriais, desmatamentos e loteamentos clandestinos.

A Lei n. 6.938, de 31 de agosto de 1981, ao dispor sobre a Política Nacional do Meio Ambiente define poluição como a "degradação da qualidade ambiental resultante de atividade que direta ou indiretamente:

a) prejudiquem a saúde, a segurança e o bem-estar da populaçâo;

b) criem condições adversas às atividades sociais e econômicas;

c) afetem desfavoravelmente a biota;

d) afetem condições estéticas ou sanitárias do meio ambiente;

e) lancem matérias ou energia em desacordo com os padrões ambientais estabelecidos".

Prossegue a Lei $n^{2} 6.938 / 81$, esclarecendo que meio ambiente é o "conjunto de condições, leis, influências e interações de ordem física, química e biológica, que nos permite, abriga e rege a vida, em todas as suas formas" (art. $3^{2}$ ). 
Ora, trata-se de situação inequívoca, na qual o legislador será obrigado a ouvir setores técnicos e científicos para elaboração de legislação específica sobre assunto tão complexo. Nestes casos, as informações, análises e pareceres de especialistas de outras ciências, deverão integrar as providências da esfera jurídica, contrario sensu prevalecerá o conservadorismo e a politicagem, comprometendo, como se verá, a eficácia das normas jurídicas.

Nem sempre as conclusões científicas são coincidentes com acordos políticopartidários ou promessas eleiçoeiras, mas devem prevalecer porque baseadas em pesquisas e experimentação, enfim, porque verdadeiras.

No caso específico da questão ambiental, as denúncias de devastação da natureza, de péssima qualidade do ar e da água, enfim, da periclitação da vida, vem a público, ou via ciências naturais, com pesquisas de químicos, físicos, biólogos, oceanógrafos, comprovando a destruição ambiental e a posteriori os historiadores, sociólogos, antropólogos ou mesmo economistas e psicólogos avaliam o comportamento do homem causador e paciente das ações danosas à natureza. Ou ocorre o contrário, são os cientistas sociais que expõem ao povo as situações nevastas ao meio ambiente e depois analisados por especialistas das ciências naturais, avaliando as dimensões do mal e as possíveis correções ou soluções.

A realidade é que graças a esta interação de conhecimentos, a História contemporânea informa que no Brasil a recente expansão urbano-industrial foi orientada pela cupidez, por ditames selváticos de um capitalismo ávido por lucros imensos e fáceis. Menosprezou-se a agricultura. $O$ homem do campo e seus valores foram vencidos pela crença absurda de que progresso significava, tão-somente, "industrialização".

O progresso industrial custou a destruição do meio ambiente. As proposições tecnocientíficas nunca foram consideradas quer pelos governos, quer pelos empresários. A atividade econômica não incorporou as descobertas ou recomendações das ciências. $\mathrm{E}$ a atividade política muito menos.

Representantes políticos somente incorporaram a questão ambiental em suas plataformas de governo na década de oitenta, após amplas denúncias da comunidade científica e de associações ambientalistas.

\section{Inteligência de Art. 225 da Constituição Federal}

O novo sistema constitucional vigente a partir de 1988 garante a todos o direito "ao meio ambiente ecologicamente equilibrado", portanto, constitui direito humano fundamental, demandando" empenho do Poder Público e de todos os cidadãos em sua preservação e respeito.

Prossegue o art. 225 da Constituição Federal, conceituando-o como "bem de uso comum do povo e essencial à sadia qualidade de vida". É res publicae; pertence ao povo. Significa a todos o direito de usufruir do bem, garantindo a todos, em compensação, a responsabilidade em preservá-lo; também o é de todos os cidadãos.

O Código Civil exemplifica-os "os bens de uso comum do povo, tais como mares, rios, estradas, ruas e praças" (art. 66), utilizando-se do critério da destinação dos bens, no caso, destinam-se ao uso coletivo. 
Nossa melhor doutrina classifica-se juntamente com os bens de uso especial entre os bens do domínio público do Estado, ou seja, "o conjunto das coisas móveis e imóveis de que é detentora a Administração, afetados quer a seu próprio uso, quer uso direto ou indireto da coletividade, submetidos a regime jurídico de direito público derrogatório e exorbitante do direito comum" (CRETELLA JUNIOR, José, Tratado do Domínio Público. Rio de Janeiro, Forense, 1984, p. 29). Para Hely Lopes Meirelles (Direito Administrativo Brasileiro, $14^{3}$ ed., Revista dos Tribunais, 1988, p. 428 ss.)"... todos os locais abertos à utilização pública adquirem esse caráter de comunidade, de uso coletivo, de função própria do povo". E mais: "Para esse uso só se admitem regulamentações gerais de ordem pública, preservadoras da segurança, da higiene, da saúde, da moral e dos bons costumes, sem particularização de pessoas ou categorias sociais". Conforme Maria Zylvia Zanella Di Pietro (Direito Administrativo, Ed. Atlas, 1990, p. 369 ss.). Trata-se, segundo Miguel S. Marienhoff (Domínio Público Protección Juridica del Usuario, Buenos Aires, Liberia Jurídica Valerio Abeledo, 1955), "de um poder que pode ser exercido por todos os homens - quivis de populo - sem distinção entre nacionais e estrangeiros, e em cujo exercício o usuário permanece sempre anônimo, indeterminado, nāo individualizado".

Enfim, o uso de bem vital para a coletividade somente pode ser disciplinado por regra geral, coercitiva, elaborada pelo conjunto dos cidadãos ou por quem legitimamente os represente, pela lei.

A defesa do meio ambiente "ecologicamente equilibrado" é dever do Poder Público, em todos os níveis (Federal, Estadual ou Municipal), imposto pela Constituição Federal, nos termos já citados, com vistas a garañtir melhor qualidade de vida para as gerações atuais e futuras.

Dispõe ainda que a intervenção humana na natureza há que ser pacífica, construtiva, enfim, respeitosa para com as espécies e ecossistemas. Seguida de fiscalização ininterrupta por parte da Administração Pública, inclusive sobre as entidades dedicadas à pesquisa.

As obras ou atividades potencialmente poluidoras dependerão de estudo prévio de impacto ambiental. A publicidade assegurará o acompanhamento pelos cidadãos dos deveres do Poder Público na proteção ambiental.

Entre esses deveres impõe-se o controle do emprego de métodos e práticas que comportem risco para a vida, a qualidade de vida e o meio ambiente.

Exige ainda providencie o Poder Público educação ambiental a todos os níveis de ensino, preparando-se assim um futuro melhor, onde o respeito ao meio ambiente consistirá sentimento natural do povo e não em imposições legais.

Destacam-se também determinações especiais, para áreas prioritárias, relativas à qualidade ambiental: "definir, em todas as unidades da Federação, espaços territoriais e seus componentes a serem especialmente protegidos, señdo a alteração e a supressāo permitidas somente através de lei, vedada qualquer utilização que comprometa a integridade dos atributos que justifiquem sua proteção". (art. 225, III).

Assim, mediante lei, poderão ser declaradas determinadas áreas de interesse para proteção ambiental, como é o caso das Áreas de Proteção Ambiental, cuja criação e utilização já são disciplinadas pela Lei n. 6.902, de 27 de abril de 1981. Daí a importância da análise de legislação existente e anterior à Constituição Federal, de 1988. 


\section{Distribuição de Competências}

A Constituição Federal de 1988, ao distribuir competências considerou dever comum à União, aos Estados, ao Distrito Federal e aos Municípios a proteção ao meio ambiente e ao combate à poluição (art. 23, VI, VII, XI). E, é evidente, que a lei constitui instrumento democrático, forte $\mathrm{e}$ justo, desde que se observe seriamente os princípios constitucionais e se busque a unicidade e coerência nos Livros Legais e sanções a serem criadas.

Para tanto, dispõe a Constituição Federal em vigor que União, Estado e Distrito Federal, deverão legislar concorrentemente sobre questões ambientais (art. 24, VI, VI, VII). Todavia, a União limitar-se-á ao estabelecimento de normas gerais (art. 24, $\S 1^{\text {l}}$ ). Urge que venha à luz Lei Complementar, a qual fixará normas para a cooperação entre os entes legiferantes.

O Estado de São Paulo, já tomou as providências conforme sua competência constitucional, dispondo a Constituição Paulista que o Estado e seus Municípios: "... providenciarão, com a participação da coletividade, a preservação, conservação, defesa, recuperação e melhoria do meio ambiente natural, artificial e do trabalho, atendidas as peculiaridades regionais e locais e em harmonia com o desenvolvimento social e econômico" (art. 191).

Note-se a inclusão dos Municípios, pois, sem a qual não serão atendidas as peculiaridades regionais e locais. A célula "mater" de nossa vida política, o Município, a que ser valorizado, sob pena de fracassar a própria política nacional para o meio ambiente.

Outro aspecto altamente positivo, diz respeito à participação da sociedade civil, não há dúvida que a colaboração das entidades ecologistas, ambientalistas foi fundamental para que os cidadãos e o próprio governo tomassem consciência e, a partir de então, providências com vistas à defesa e recuperação do meio ambiente:

\section{Legislação Pertinente}

\section{a) Legislação Federal (Proteção Ambiental).}

1. Decreto-Lei $n^{\mathfrak{Q}} 1.413$, de 14 de agosto de 1975 .

Dispõe sobre o controle da poluição do meio ambiente, provocada por atividades industriais, inclusive áreas críticas.

2. Decreto $\mathrm{n}^{\mathrm{e}} \mathbf{7 6 . 3 8 9}$, de 03 de outubro de 1975 .

Dispõe sobre as medidas de prevenção e controle da poluição industrial, de que trata o Decreto-Lei $n^{2} 1.413 / 75$ e dá outras providências.

3. Lei $\mathrm{n}^{2} 6.902$, de 27 de abril de 1981.

Dispõe sobre a criação de Estações Ecológicas, Áreas de Proteção Ambiental e dá outras providências. 
4. Lei $n^{2} 6.938$, de 31 de agosto de 1981.

Dispõe sobre a Política Nacional do Meio Ambiente, seus fins e mecanismos de formulação e aplicação, e dá outras providências.

5. Decreto ne 91.145 , de 15 de março de 1985.

Cria o Ministério do Desenvolvimento Urbano e Meio Ambiente, dispõe sobre sua estrutura, transferindo-lhe os órgãos que menciona, e dá outras providências.

6. Lei $\mathrm{n}^{\mathrm{Q}} 7.804$, de 18 de julho de 1989. $6.902 / 87$.

Altera a Lei $n^{\mathcal{Q}} 6.938 / 81$, a Lei $n^{\mathcal{Q}} 7.735 / 89$, a Lei $n^{\mathcal{Q}} 6.803 / 80$ e a Lei $n^{\mathcal{Q}}$

\section{b) Legislação Estadual (Proteção Ambiental).}

7. Lei $\mathrm{n}^{\mathrm{Q}}$ 997, de 31 de maio de 1971.

Dispõe sobre o controle da poluição do meio ambiente.

8. Decreto $\mathrm{n}^{\circ} 8.488$, de 08 de setembro de 1971.

Aprova o Regulamento da Lei ${ }^{2}$ 997/76.

9. Decreto $\mathrm{n}^{\mathrm{9}} 10.229$, de 29 de agosto de 1977.

Acrescenta dispositivo ao Regulamento aprovado pelo Decreto $n^{\mathfrak{Q}} 8.488 / 71$.

10. Lei Complementar $\mathrm{n}^{2} 171$, de 15 de dezembro de 1977.

Acrescenta incisos ao artigo $4^{\circ}$ do Decreto-Lei Complementar $\mathbf{n}^{2} 9$, de 31 de dezembro de 1969.

11. Lei Complementar $\mathrm{n}^{2} 179$, de 10 de maio de 1978.

Dá nova redação ao inciso VIII do artigo 4. do Decreto-Lei Complementar $\mathrm{n}^{\mathcal{Q}}$ 9, de 31 de dezembro de 1969, acrescido pela Lei Complementar $\mathrm{n}^{\mathcal{1}}$ 171/77.

12. Decreto $\mathrm{n}^{\mathrm{e}} 12.045$, de 08 de agosto de 1978 .

Altera o artigo 116, do Regulamento aprovado pelo Decreto $\mathrm{n}^{\circledR} 8.468 / 76$.

13. Decreto $\mathrm{n}^{\mathrm{Q}} 13.069$, de 29 de dezembro de 1978.

Aprova Normas Técnicas Especiais, relativas ao Saneamento Ambiental nos Loteamentos Urbanos ou para fins urbanos.

14. Decreto $\mathrm{n}^{\mathrm{0}} 15.424$, de 23 de julho de 1980 .

Acrescenta dispositivos e procede alteraçōes que especificam ao

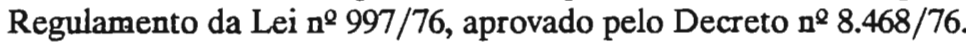

15. Decreto $\mathrm{n}^{2}$ 16.266, de 02 de dezembro de 1980.

Altera o Anexo ao Regulamento aprovado pelo Decreto $\mathrm{n}^{\mathcal{Q}} 8.468 / 76$, acrescentado pelo artigo $6^{Q}$ e baixado pelo artigo 11 , todos do Decreto $n^{\mathcal{Q}} 15.425 / 80$. 
16. Decreto $\mathrm{n}^{\mathrm{Q}} 17.299$, de 07 de julho de 1981.

Dá nova redação aos artigos que especifica, todos do Regulamento aprovado pelo Decreto $\mathrm{n}^{\mathfrak{Q}} 84 / 68$, e dispóe sobre medida correlata.

17. Decreto $\mathrm{n}^{\mathbf{2}} 20.903$, de 26 de abril de 1983.

Cria o Conselho Estadual do Meio Ambiente.

18. Lei $\mathrm{n}^{\mathrm{Q}} 3.743$, de 09 de julho de 1983.

Estabelece normas de estímulo para a criação de Parque Ecológico e de Parques Florestais nos Municípios.

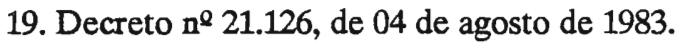

Acrescenta dispositivos ao artigo $2^{\circ}$, do Decreto $\mathrm{n}^{\mathfrak{Q}} 20.903 / 83$.

20. Lei $\mathrm{n}^{\mathrm{9}} 4.055$, de 04 de junho de 1984.

Declara área de proteção ambiental a região urbana e rural do Município de Cajamar.

21. Lei $\mathrm{n}^{\mathrm{Q}} 4.529$, de 18 de janeiro de 1985.

Dispõe sobre o uso e a ocupação do solo na região da Serra do Itapeti, com vistas à proteção e melhoria da qualidade do meio ambiente na Região Metropolitana de São Paulo.

\section{c) Legislação Federal (Zoneamento Industrial)}

22. Lei $n^{9} 6.803$, de 02 de julho de 1980.

Dispõe sobre as diretrizes básicas para o zoneamento industrial nas áreas críticas de poluição e dá outras providências.

\section{d) Legislação Estadual (Zoneamento Industrial)}

23. Lei $\mathrm{n}^{\mathrm{Q}} 1.817$, de 27 de outubro de 1978.

Estabelece os objetivos e as diretrizes para o desenvolvimento industrial metropolitano e disciplina o zoneamento industrial, a localização, a classificação e o licenciamento de estabelecimentos industriais na Região Metropolitana da Grande São Paulo, e dá providências correlatas.

24. Decreto $\mathrm{n}^{\mathrm{Q}} 13.095$, de 05 de janeiro de 1978.

Aprova o Regulamento da Lei $\mathrm{n}^{\mathrm{Q}} 1.817 / 78$, nas matérias relativas à localização, à classificação, ao licenciamento de estabelecimentos industriais da Grande São Paulo e sua fiscalização.

25. Lei $\mathrm{n}^{2} 2.952$, de 15 de julho de 1981.

Altera o Quadro II, a que se refere o artigo $8^{\circ}$ da Lei $n^{Q} 1.817 / 78$. 
26. Lei $\mathrm{n}^{2} 3.811$, de 30 de agosto de 1983.

Altera disposição da Lei $n^{\mathcal{Q}} 1.817 / 78$, na parte referente à classificação de zonas de uso industrial.

\section{e) Legislação Estadual (Proteção aos Mananciais)}

27. Lei $\mathrm{n}^{\mathrm{e}} 898$, de 18 de dezembro de 1975.

Disciplina o uso do solo para a proteção dos mananciais, cursos e reservatórios de água e demais recursos hídricos de interesse da Região Metropolitana da Grande São Paulo, e dá outras providências correlatas.

28. Lei $\mathrm{n}^{\mathrm{9}}$ 1.172, de 17 de novembro de 1976.

Delimita as áreas de proteção relativas aos mananciais, cursos e reservatórios de água a que se refere o artigo $2^{\ell}$ da Lei $\mathrm{n}^{\mathcal{Q}} 898 / 70$, estabelece normas de restrição do uso do solo em tais áreas e dá providências correlatas.

29. Decreto $\mathrm{n}^{2} 9.714$ de 19 de abril de 1977.

Aprova o Regulamento das Leis $n^{\circ} 898 / 75$ e 1.172/76.

30. Decreto $n^{\varrho} 10.755$, de 22 de novembro de 1977.

Dispõe sobre o enquadramento dos corpos de água receptores na classificação prevista no Decreto $n^{0} 8.468 / 76$.

31. Decreto $\mathrm{n}^{\mathrm{Q}} 12.219$, de $1^{\mathrm{Q}}$ de setembro de 1978.

Autoriza a Secretaria dos Negécios Metropolitanos a celebrar convênios com os Municípios da Região Metropolitana da Grande São Paulo, para aprovação de projetos de residências unifamiliares, em áreas de proteção aos mananciais metropolitanos, estabelecidos pelas Leis $n^{\ell}$ s. 898/75 e 1.172/76.

32. Lei n 2.177, de 26 de novembro de 1979 .

Altera o inciso IX do artigo $2^{2}$ da Lei $898 / 75$.

33. Decreto $\mathrm{n}^{\mathrm{Q}} \mathbf{1 5 . 0 3 7}$, de 06 de maio de 1980.

Regulamenta a Lei $n^{\mathcal{Q}} 2.177 / 89$, delimitando os novos perímetros das áreas de proteção formadas pela bacia hidrográfica do Rio Guaiá.

34. Lei n 3.286, de 18 de maio de 1982.

Dá nova redação ao inciso XI do artigo $2^{2}$, da Lei $n^{\mathcal{Q}} 898 / 75$. 


\section{Bibliografia}

CRETELLA JUNIOR, José. Comentários à Constituiçāo Brasileira de 1988. Rio de Janeiro : Forense, 1989.

. Tratado de "domine" público. Rio de Janeiro : Forense, 1984.

DALLARI, Dalmo de Abreu. O que são direitos da pessoa. São Paulo : Brasiliense, 1983.

DALLARI, Dalmo de Abreu. Viver em sociedade. São Paulo : Moderna, 1985.

DI PIETRO, Maria Sylvia Zanella. Direito administrativo. São Paulo : Atlas, 1990.

FERREIRA FILHO, Manoel Gonçalves. Idéias para a Nova Constituição. São Paulo : Saraiva, 1987.

LEGISLAÇÃO básica de interesse metropolitano. São Paulo : Empresa Metropolitana de Planejamento da Grande São Paulo. 1985.

MEIRELLES, Hely Lopes. O Direito Administrativo Brasileiro. São Paulo : Ed. Revista dos Tribunais, 1988.

SIlVA, José Afonso da. Curso de Direito Constitucional Positivo. São Paulo : Ed. Revista dos Tribunais, 1989.

São Paulo, janeiro de 1990. 